\title{
An Analysis of Power System Stability against Hyperchaotic Noises and Blackouts
}

\author{
Hakan Öztürk $10, *, 1$ \\ ${ }^{\alpha}$ Electrical and Electronic Engineering, Faculty of Engineering and Natural Sciences, Istanbul Medeniyet University, Istanbul, Turkey, ${ }^{*}$ Electrical and \\ Electronics Engineering, Institute of Natural Sciences, Sakarya University, Sakarya, Turkey.
}

\begin{abstract}
This study investigates the power systems that involve various numbers of busbars. To prevent the disturbances and instabilities in the power systems, power system stabilizers and various control methods have been used. A hyperchaotic blackout has been created by using an existing hyperchaotic system. Hyperchaotic voltage collapse and hyperchaotic disturbance have been injected to the test systems. The situations of the various power systems are illustrated under proposed hyperchaotic blackout and noise. The stability analysis of the power system has been executed according to the dynamic features of hyperchaos.
\end{abstract}

\section{KEYWORDS}

Chaos theory

Hyperchaos

Power system

stability

Power flow

Blackouts

\section{INTRODUCTION}

Power System Stabilizers (PSS) are used to damp low-frequency oscillations in the range of $0.2 \mathrm{~Hz}$ to $2.5 \mathrm{~Hz}$. The automatic voltage regulator (AVR) improves the terminal voltage of the generator by controlling the amount of current supplied from the exciter to the generator field winding. Thus, the generator excitation system maintains generator voltage and controls the reactive power flow using an automatic voltage regulator. It is mainly used to dampen oscillations that occur during load changes in the power system. It keeps the generator terminal voltage constant, so that the voltage on the load side remains almost constant even if the load changes with time. Therefore, the stability of the AVR system would seriously affect the security of the power system. AVR helps to improve the steady-state stability of power systems, but transient stability has become a problem for power system operators. To improve system damping, the generator is equipped with a PSS, which provides an additional feedback stabilization signal in the excitation system (DELAVARİ and BAYAT 2015; Demello and Concordia 1969; Sauer and Pai 1998).

In the literature, large number of studies about the hyperchaos that has been recently discovered exist. (Rossler 1979) first introduced the hyperchaotic systems and has enabled it to be used in many studies such as this study. Various analyses were executed about the hyperchaos in the papers such as (Matsumoto et al. 1986;

Manuscript received: 29 July 2021,

Revised: 7 September 2021,

Accepted: 10 September 2021.

${ }^{1}$ hakan.ozturk.eee@gmail.com, hakan.ozturk@medeniyet.edu.tr (Corresponding Author)
Wang and Wang 2008; Li and Chen 2004; Li et al. 2005; Fonzin Fozin et al. 2019; Rössler and Letellier 2020; Vaidyanathan et al. 2020; Rech 2017) It is possible to reach hyperchaotic systems in many fields such as control theory (Fonzin Fozin et al. 2019), synchronization (Sajjadi et al. 2020; Tian et al. 2019), secure communication applications (Yu et al. 2019; Xiu et al. 2021) and image encryption (Yuan et al. 2017; Liu et al. 2019; Zhu and Zhu 2020). The corresponding topic of this study is power system stability. The recent state of its literature can be summarized by mentioning the following studies that optimizing the parameters of power systems (Huang et al. 2017; Ahsan and Mufti 2020). The studies that improve the power system stability by proposing a novel whale optimization algorithm (Kumar et al. 2021; Sahu et al. 2018), energy reshaping (Dong et al. 2017), FACTS devices (Singh and Agnihotri 2018; Van Dai et al. 2017), UPFC Based on Neuro-Fuzzy Method (Jamal et al. 2017) and wide area fuzzy-2 logic based damping controller Sharma et al. (2017) exist. The most of analyses about the power system stability aim to enhance the stability of the test system by proposing novel control methods. However, relating analyses have been executed under ordinary faults that have short time and are linear.

The chaos in power systems is basically investigated in (Yu et al. 2003; Chiang et al. 1993) in the simple power systems. Amongst the studies that includes chaos with power systems, Chen et al. (2005) presented the bifurcation in a SMIB system. (Harb and Abdel-Jabbar 2003) controlled bifurcation in a small power system. Nangrani and Bhat (2018) proposed a fractional order controller, and Das et al. (2021) proposed a PID Sliding Mode Controller for chaotic power systems. Previous studies have not elaborated the analyze of power systems and have not comprised sufficient benchmark. This study aims to make a more detailed analysis on the topic, and present a superior hyperchaotic situation. 
This study basically recounts the corresponding power system stabilizers in Section 2. The hyperchaotic system and how it is considered as a blackout are shown in Section 3. The hyperchaotic blackout is introduced in the test systems such as two-area model, Heffron-Philips model that involve infinite bus, single machine infinite bus system in Section 4 . The detailed stability analysis has been made in section 5 . Finally, the conclusions in the study have been presented in Section 6.

\section{THE POWER SYSTEM STABILIZERS}

The power system stabilizers have been used to add damping to electromechanical oscillations and optimize the system. They operate basically the production of electrical torque proportional to the speed change through the generator's excitation system. The PSS is one of the supplementary controllers, which is often applied as part of the excitation control system. Grid codes and regulatory agencies are increasingly specifying PSS controls for new generation and retrofit on existing units. In the excitation system, PSS applies a signal creating electrical torques that damp out power oscillations and it is the main function of the PSS. The transfer function of the PSS (Ekinci and Hekimoglu 2018) is simply given as Eq. 1.

$$
V(s)=K_{P S S}\left(\frac{1+s T_{1}}{1+s T_{2}}\right) \Delta \omega(s)
$$

The PSS response control, part of the integrated generator control system, provides an additional signal that can be added to the Automatic Voltage Regulator (AVR) input. By adding the stabilization signal, the PSS should generate an electrical torque component that counteracts the mechanical dynamics. The electrical torque component generated should be in phase with the generator rotor speed deviations to be able to damp the oscillations. The main structure of PSS has been shown as Figure. 1 and it has been used widely.

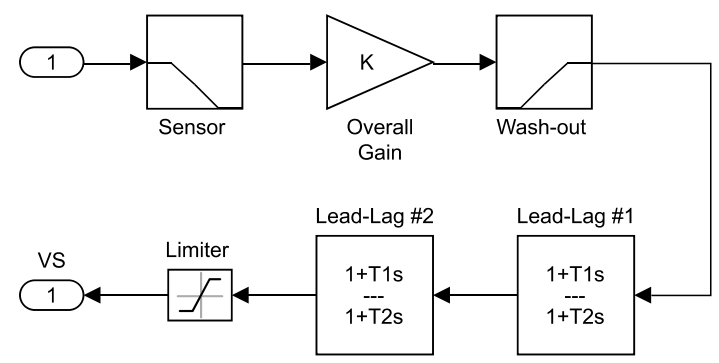

\section{Figure 1 Block Diagram of PSS}

The generic configuration of the PSS in a power system is depicted in Fig. 2. The PSS is not usually utilized as alone. In the power systems, various control models and devices have been accompanied the PSS. The AVR is the primary of these devices. Flexible alternating current transmission system (FACTS), static VAR compensator (SVC) and thyristor-switched reactor (TSR) are amongst the mentioned devices.

Additionally, numerous control methods such as decentralized modal control, fuzzy logic control, PID control and adaptive fuzzy sliding mode control have been developed. Hybrid methods are also proposed in terms of accordance and robustness. These methods are also improved with metaheuristic optimization algorithms. Hence, power system stability has been aimed to improve by means of the corresponding methods.

\section{DESIGN OF THE POWER SYSTEM BASED ON HYPER- CHAOS}

The generic control model of PSS and AVR is seen in Figure 2. In the control system, the reference is generally taken as $1 \mathrm{pu}$. The PSS has used the rotor speed deviation of the generator. Automatic voltage regulator (AVR) regulates the excitation voltage of the exciter.

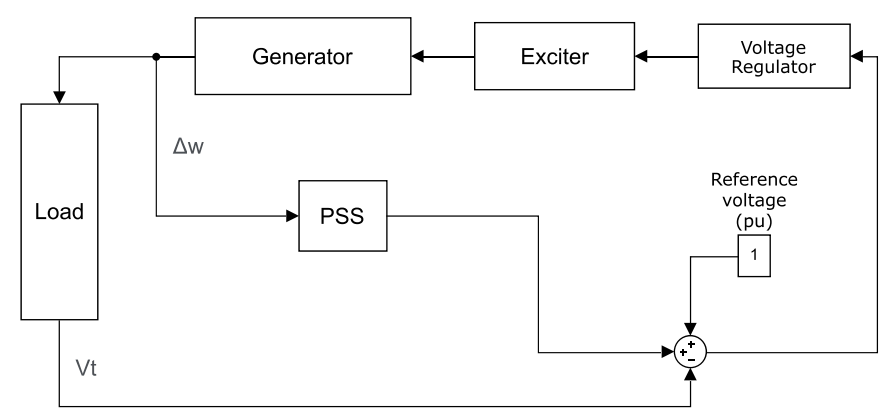

Figure 2 Conventional power system model

The generic equations of the power system models have been listed in Eq. 2 - 6. In Eq. 2, $\Delta w(t)$ represents the speed deviation, is loaded by hyperchaotic oscillator. In Eq. 6, reference voltage is consisted of a set of equations that given in Eq. 7 - 10.

$$
\begin{gathered}
w(t)=w_{0}+\Delta w(t) \\
\Delta w(t)=\frac{1}{2 H} \int_{0}^{t}\left(T_{m}-T_{e}\right) d t-K_{d} \Delta w(t) \\
\frac{d \delta_{i}}{d t}=w_{i}-w_{r e f} \\
\frac{d w_{i}}{d t}=\frac{\left(-D_{i}\left(w_{i}-w_{r e f}\right)+P_{m i}-P_{G i}\right)}{M_{i}} \\
\frac{d E_{f d}}{d t}=\left(-E_{f d}+K_{a}\left(V_{r e f}+V_{s}-V\right)\right) / T_{a}
\end{gathered}
$$

Where the $w(t)$ is the speed or frequency, $\mathrm{H}$ is inertia constant that is inversely proportional to noise, nomenclature $\mathrm{T}$ is the reciprocating torques, $K_{d}$ is damping coefficient, $\delta$ is load angle, $\mathrm{D}$ is damping factor, $P_{m i}$ is real power generated, $\mathrm{M}$ is angular torque, $P_{G i}$ is output electrical power of the generator, $E_{f d}$ is field voltage, $V_{s}$ is terminal voltage, $K_{a}$ is gain of the excitation system, Eq. 2 - 6 are basic equations of power systems.

The PSS is implemented in power systems and is investigated under various faults and disturbances. Reference voltage indicates that the type of disturbance and fault. The reference voltage is replaced by an oscillator that is obtained from well-known Rossler attractor (Rossler 1979) as follows:

$$
\begin{gathered}
V_{r e f 1}^{\cdot}=-\left(V_{r e f 2}+V_{r e f 3}\right) \\
V_{r e f 2}^{\cdot}=V_{r e f 1}+\alpha V_{r e f 2}+V_{r e f 4} \\
V_{r e f 3}^{\cdot}=b+V_{r e f 1} V_{r e f 3} \\
V_{r e f 4}^{\cdot}=-c V_{r e f 3}+d V_{r e f 4}
\end{gathered}
$$


Reference voltages are given to the test system where $\alpha=0.25$, $\mathrm{b}=3, \mathrm{c}=-0.5$ and $\mathrm{d}=0.05$. The initial conditions are set as $V_{\text {ref } 1}(0)=$ $-10, V_{\text {ref } 2}(0)=-6, V_{\text {ref } 3}(0)=0$ and $V_{\text {ref } 4}(0)=10.1$. Each generator is supplied by hyperchaotic oscillator voltage instead of normal reference voltage.

As a signal of noise, $\Delta w(t)$ is similarly replaced by the equations of well-known Rossler attractor. Equation model of the power system is basically transformed into follows:

$$
\begin{gathered}
w_{1}(t)=w_{0}-\int\left(\Delta w_{2}+\Delta w_{3}\right) d t \\
w_{2}(t)=w_{0}+\int\left(\Delta w_{1}+\alpha \Delta w_{2}+\Delta w_{4}\right) d t \\
w_{3}(t)=w_{0}+\int\left(b+\Delta w_{1} \Delta w_{3}\right) d t \\
w_{4}(t)=w_{0}+\int\left(-c \Delta w_{3}+d \Delta w_{4}\right) d t \\
\Delta w(t)=\frac{1}{2 H} \int_{0}^{t}\left(T_{m}-T_{e}\right) d t+K_{d} \int\left(\Delta w_{2}+\Delta w_{3}\right) d t
\end{gathered}
$$

\section{PROPOSED HYPERCHAOTIC BLACKOUT FOR THE CASES}

\section{Case 1 : 11 Buses and 4 machines system}

This system consists of two largely symmetrical areas connected by two $230 \mathrm{kV}$ lines twice $110 \mathrm{~km}$ long. Each has two identical rotary generators with a rated power of $20 \mathrm{kV} / 900 \mathrm{MVA}$. The parameters of the synchronous machines are all the same except for the inertia, which is $\mathrm{H}=6.5 \mathrm{~s}$ for the area 1 machines and $\mathrm{H}=4 \mathrm{~s}$ for the area 2 machines. The load flow in this case (with generator 2 as the slack machine) is such that all generators in the system produce about $700 \mathrm{MW}$ each. The loads are assumed to be constant impedance load models throughout, with the loads for Area 1 and 2 being 976 MW and 1765 MW respectively. To improve the voltage profile, capacitors were added in each area, can be seen in Figure 3.

This system is also referred as Kundur's two-area system and its features can be summarized as follows:

- Two loads are comprised to the test system at bus 7 and 9;

- Both areas have been provided with the fundamental frequency $60 \mathrm{~Hz}$;

- Two shunt capacitors are connected to bus 7 and 9;

- The system is consisted two similar areas connected by a transmission line.;

Each generators of the system (G1, G2, G3, G4) in Figure 3 have been connected with the 4-D hyperchaotic system (Sheikh and Starrett 2015). The other parameters are not changed and power system stabilizers are activated taking into account the cases.

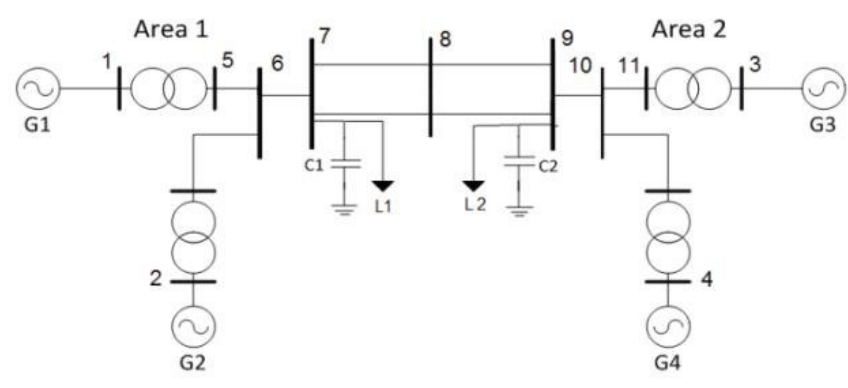

Figure 3 Four machines or two-area test system (Sheikh and Starrett 2015)

\section{Case 2 : Infinite Bus Power System}

Heffron-Phillips model of the synchronous generator is a fourthorder linear model with a third-order synchronous machine and a first-order AVR. This model is suitable for the analysis of small signals where a linear approximation is reasonable. Therefore, all input and output signals of this model have variations with a small range around the nominal value represented by nomenclature "Delta". The block diagram of the linear model is shown in Figure 4.

- Heffron-Phillips model is widely studied in small signal stability analysis, also for off-line design of power system stabilizers;

- The parameters are mostly processed using the parameters of synchronous generator and system variables at steady-state conditions;

- The model can be modified according to proposed control algorithm. 


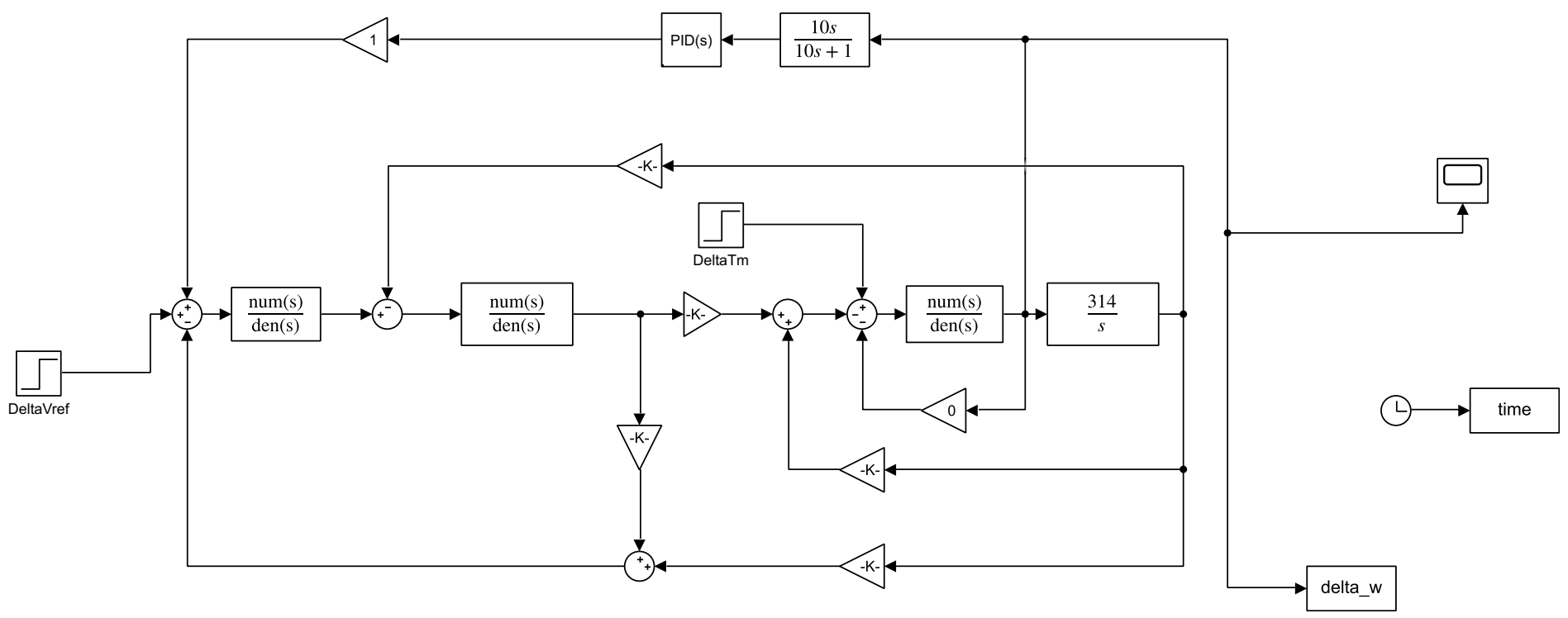

Figure 4 The Heffron-Phillips Model that involve infinite bus

\section{Case 3 : SMIB system}

Single machine-infinite bus system (SMIB) is a basic system that is consisted of a generator, a transformer, the transmission line, a source, high impedance and infinite bus as Fig. 5. In this study line reactance is taken as $100 \mathrm{ohm}$ and $1000 \mathrm{VA}$ synchronous machine is selected. The main features of the test systems are denoted in Table 1. The excitation voltage of the machine is connected with hyperchaotic oscillator. It is aimed to consider under single phase-hyperchaotic blackout.

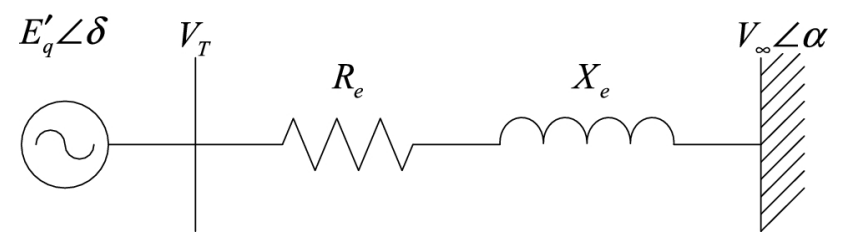

Figure 5 SMIB system model

\section{STABILITY FINDINGS FOR THE CASES}

Stability refers to a power system's tendency to create restorative forces that are equal to or larger than the disturbing forces in order to preserve equilibrium. Problems with power system stability are often classified into two categories: steady state and transient. The ability of the power system to reestablish synchronism after modest or slow shocks, such as a gradual power change, is referred to as steady-state stability. Dynamic stability is a subset of steadystate stability. With the addition of automatic control mechanisms, dynamic stability is concerned with tiny disruptions enduring for a long time. Transient stability is concerned with the impacts of large, sudden disruptions such as fault onset, line loss, and load application or removal.

\section{Results for Case 1}

The mentioned tests for the cases have been realized in Matlab Environment. The results of the test for two areas system have been depicted in Figs. 6-11. The corresponding results are obtained from the system that is injected with hyperchaotic voltage. Accordingly, the balance of the speed deviation is not overly disturbed as it can be seen in Fig. 6. In the generator voltages and load angle, the oscillations that instantaneously increase with some time intervals are occured as Figs. 7-8. Once PSS restorer is activated, the case can be seen in Figs. 10-11. The power system stabilizers have increased the magnitude of violent voltage swells and had a negative impact. The power system stabilizers have caused to worsen small signal stability, too.

For voltage stabilty evaluation, PV curve is obtained as Fig. 12. In the first state, there is no points under the saddle point and the system is stable. In Fig. 13 tornado type curve obtained instead of nose curve as Power-Voltage characteristic has been shown. The power-voltage characteristic in hyperchaotic blackout has included large number of noses. It indicates that many critical eigen values are found in power system. 
Table 1 Standart values for the test systems

\begin{tabular}{lllll} 
Test Model & Speed Deviation & Voltage $(\mathrm{V})$ & Frequency $(\mathrm{Hz})$ & Power (VA) \\
\hline Two-area system & $0.0024 \mathrm{pu}$ & $20 \mathrm{kV}$ & $60 \mathrm{~Hz}$ & $900 \mathrm{MVA}$ \\
Infinite bus power system & $0 \mathrm{rad} / \mathrm{s}$ & $400 \mathrm{~V}$ & $60 \mathrm{~Hz}$ & - \\
SMIB system & $-0.0013 \mathrm{rad} / \mathrm{s}$ & $220 \mathrm{~V}$ & $60 \mathrm{~Hz}$ & $1 \mathrm{kVA}$ \\
\hline
\end{tabular}

Table 2 Noise characteristics of power systems for the cases

\section{Speed deviation}

\begin{tabular}{|c|c|c|c|c|}
\hline \multirow[t]{2}{*}{ Test Type/Model } & \multicolumn{2}{|c|}{ Hyperchaotic Blackout } & \multicolumn{2}{|c|}{ Damping Characteristic } \\
\hline & Mean Value & Maximum Value & Mean Value & Maximum Value \\
\hline Two-area system (G1) & $0.0509 \mathrm{pu}$ & $0.1769 \mathrm{pu}$ & $0.02765 \mathrm{pu}$ & $0.1164 \mathrm{pu}$ \\
\hline Two-area system (G2) & $0.0520 \mathrm{pu}$ & $0.1816 \mathrm{pu}$ & $0.02836 \mathrm{pu}$ & $0.1181 \mathrm{pu}$ \\
\hline Two-area system (G3) & $0.3277 \mathrm{pu}$ & $0.4977 \mathrm{pu}$ & $0.2466 \mathrm{pu}$ & $0.4265 \mathrm{pu}$ \\
\hline Two-area system (G4) & $0.3034 \mathrm{pu}$ & $0.4671 \mathrm{pu}$ & $0.2456 \mathrm{pu}$ & $0.4234 \mathrm{pu}$ \\
\hline Infinite bus system & $0.0007 \mathrm{rad} / \mathrm{s}$ & $0.2342 \mathrm{rad} / \mathrm{s}$ & $0.0007 \mathrm{rad} / \mathrm{s}$ & $0.169 \mathrm{rad} / \mathrm{s}$ \\
\hline SMIB system & $-0.7211 \mathrm{rad} / \mathrm{s}$ & $512 \mathrm{rad} / \mathrm{s}$ & $-0.6891 \mathrm{rad} / \mathrm{s}$ & $128 \mathrm{rad} / \mathrm{s}$ \\
\hline
\end{tabular}

Table 3 Frequency stability of two-area system

Frequency $(\mathrm{Hz})$

\begin{tabular}{|c|c|c|c|c|}
\hline \multirow[t]{2}{*}{ Test Type/Model } & \multicolumn{2}{|c|}{ Hyperchaotic Blackout } & \multicolumn{2}{|c|}{ Damping Characteristic } \\
\hline & Mean Value & Maximum Value & Mean Value & Maximum Value \\
\hline Two-area system (G1) & $60 \mathrm{~Hz}$ & $60.75 \mathrm{~Hz}$ & $60 \mathrm{~Hz}$ & $60.72 \mathrm{~Hz}$ \\
\hline Two-area system (G2) & $60.06 \mathrm{~Hz}$ & $61.29 \mathrm{~Hz}$ & $60.04 \mathrm{~Hz}$ & $61 \mathrm{~Hz}$ \\
\hline Two-area system (G3) & $61.28 \mathrm{~Hz}$ & $80.54 \mathrm{~Hz}$ & $62.10 \mathrm{~Hz}$ & $82.65 \mathrm{~Hz}$ \\
\hline Two-area system (G4) & $61.88 \mathrm{~Hz}$ & $83.65 \mathrm{~Hz}$ & $62.07 \mathrm{~Hz}$ & $81.75 \mathrm{~Hz}$ \\
\hline
\end{tabular}




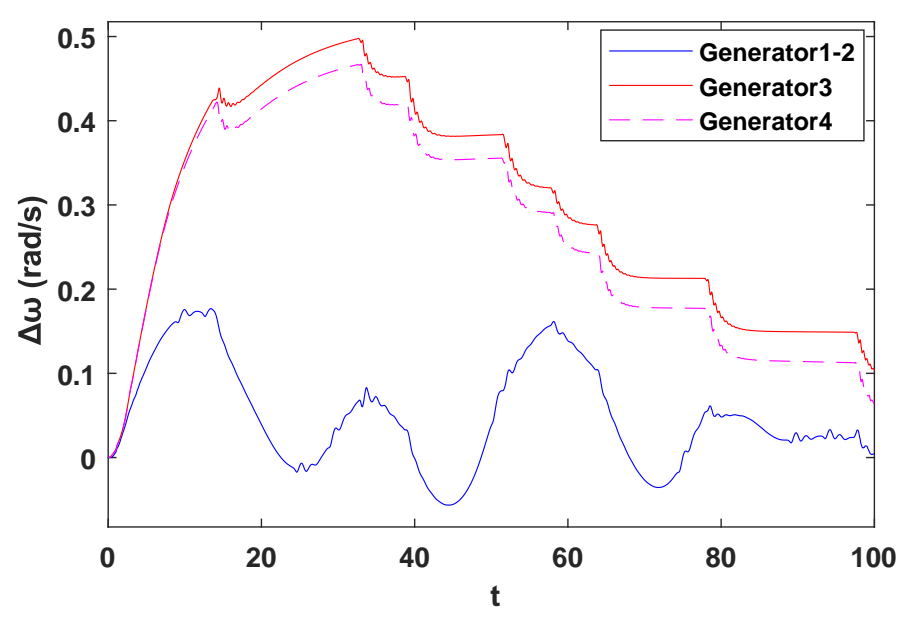

Figure 6 Speed deviation of generators against hyperchaotic noise

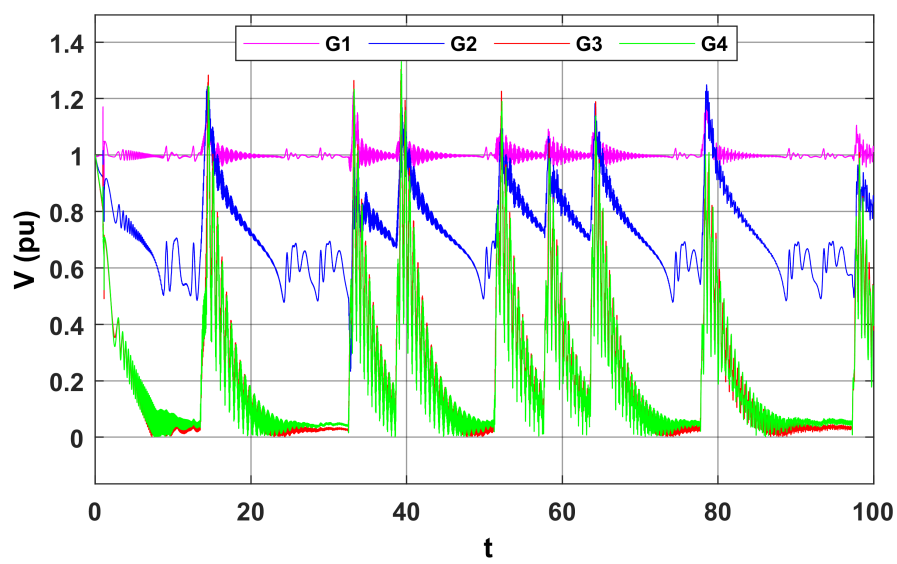

Figure 7 Generator voltages against hyperchaotic noise

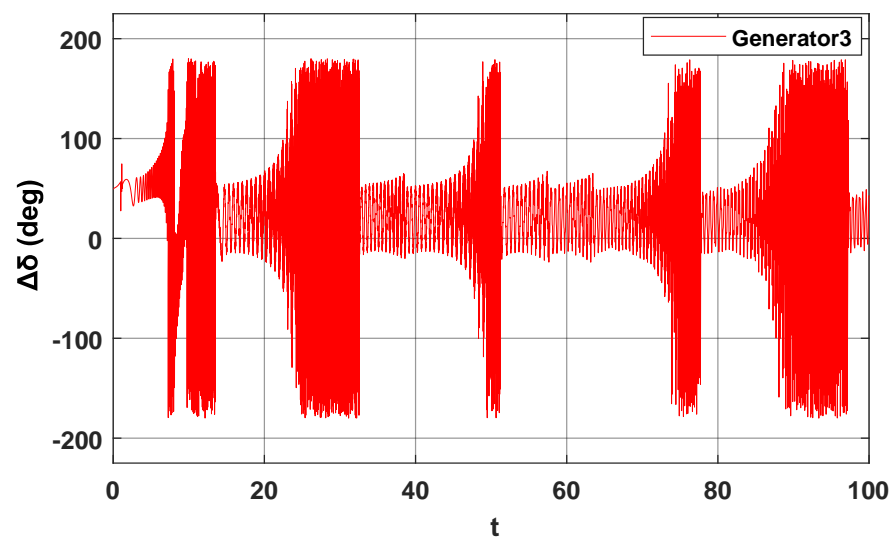

Figure 8 Load angle of generator 3 against hyperchaotic noise

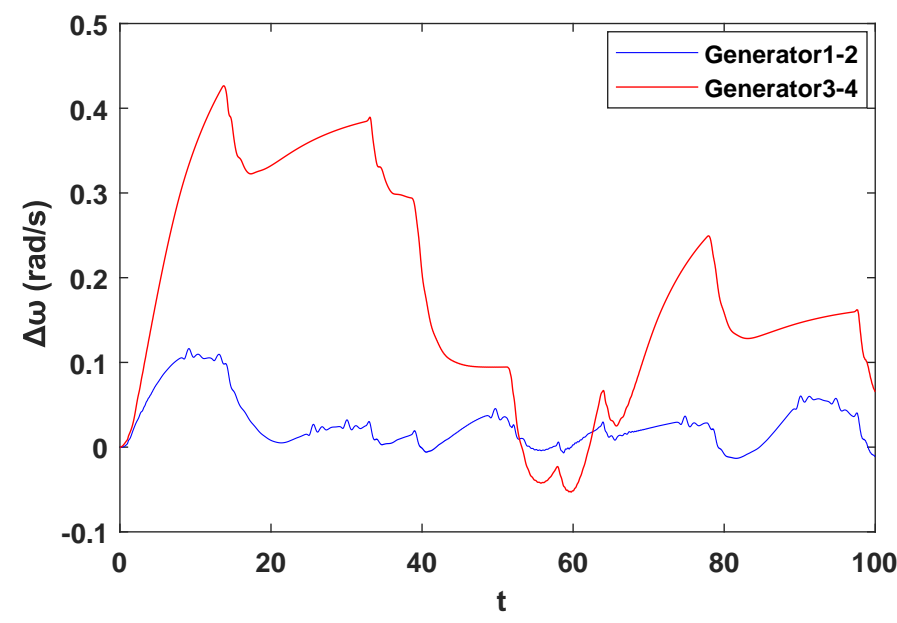

Figure 9 Speed deviation of generators against hyperchaotic noise when PSS is activated

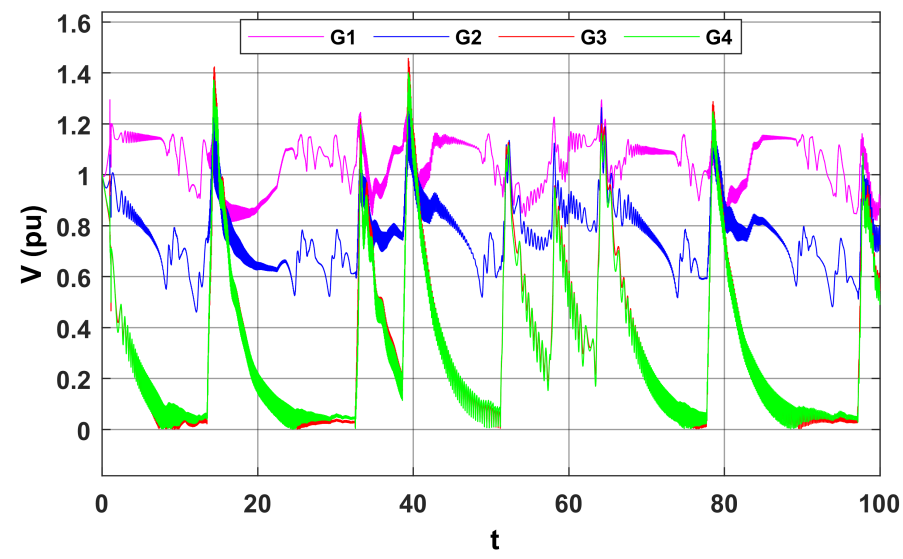

Figure 10 Generator voltages against hyperchaotic noise when PSS is activated

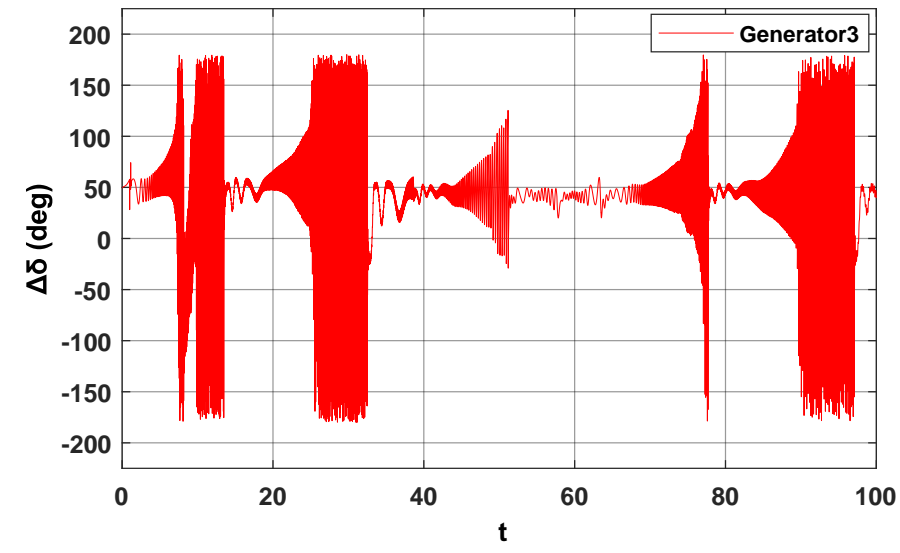

Figure 11 Load angle of generator 3 against hyperchaotic noise when PSS is activated 


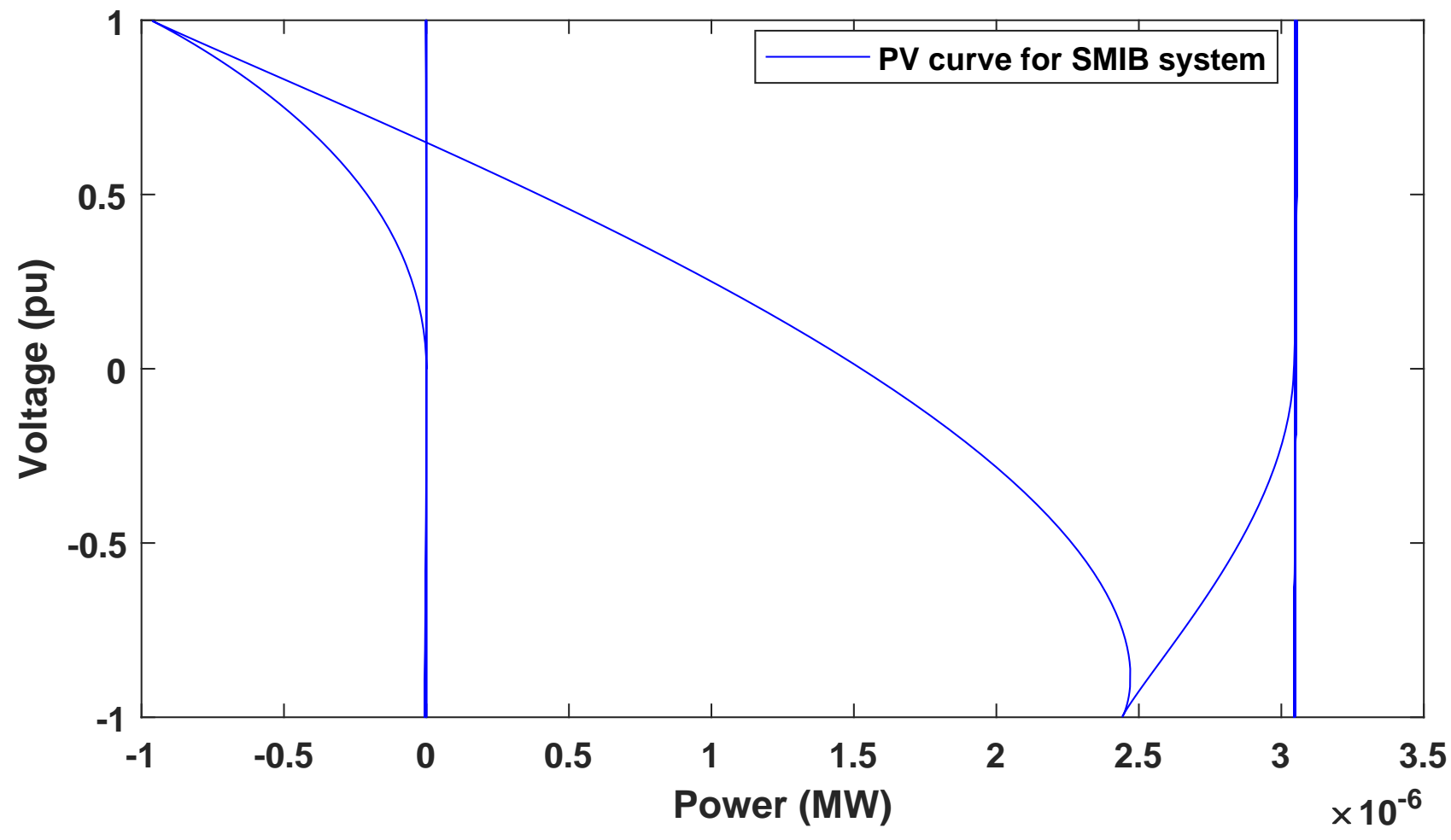

Figure 12 The standart P-V curve (Nose curve) for SMIB system

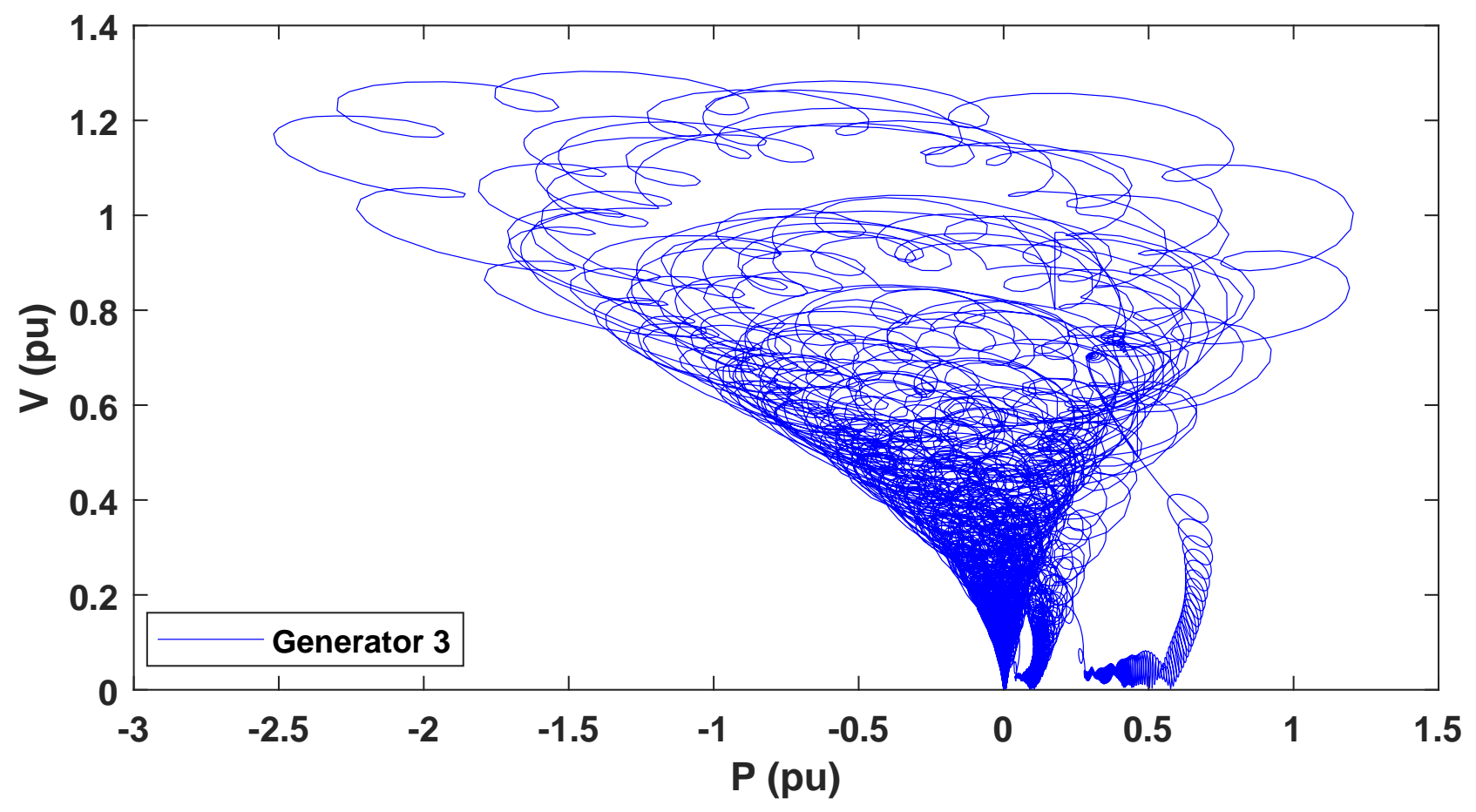

Figure $13 \mathrm{P}-\mathrm{V}$ curve during hyperchaotic blackout 
According to the results in Table 2, the stability of generator 3 and generator 4 have been more reduced than that of generator 1 and generator 2. PSS could not be very effective for them. The frequency values for the cases have been given in Table 3. In two-area system, generator 1 and generator 2 have been bordered on stability. In generator 3 and generator 4 , very high frequency instability occurred. The PSS has not been very advantageous for the devastating blackouts.

\section{Results for Case 2}

In the second case, infinite-bus model is used to analyze hyperchaotic blackout characteristics. The generators showed more oscillations than that of standart noises. Unlike standart noises in power systems, very small and ineque oscillations have been observed. The PID controlled PSS have filtered the small noises in the generators. It can be seen by the variety between the Fig. 14 and Fig. 15. However, high magnituded noises could not be prevented.

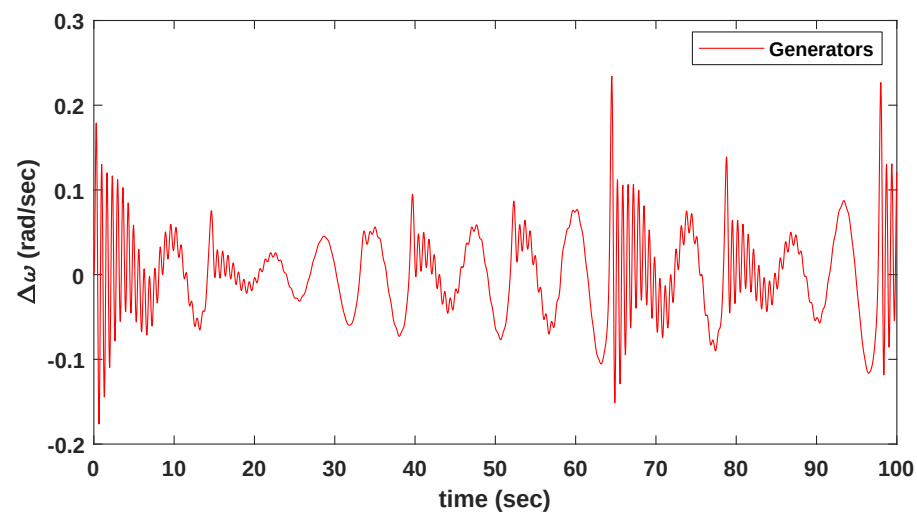

Figure 14 Speed deviation of generators against hyperchaotic noise in infinite bus power system

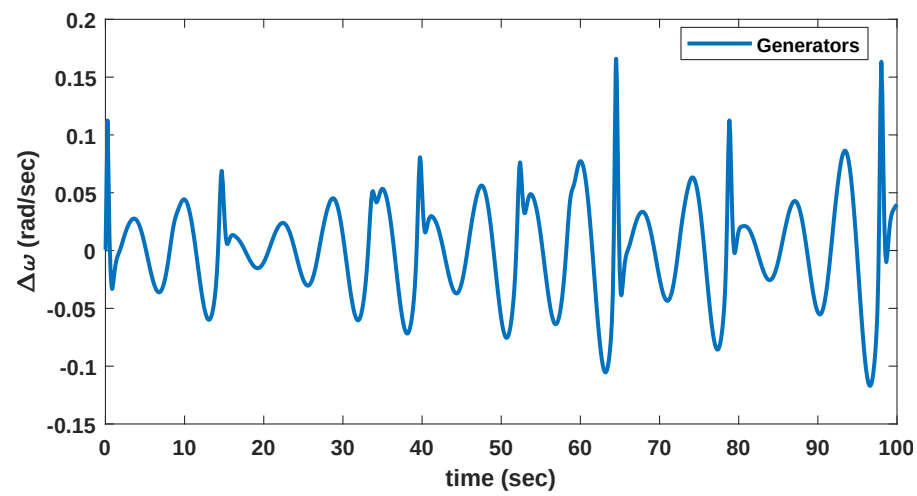

Figure 15 Speed deviation of generators against hyperchaotic noise with PID controlled PSS in infinite bus power system

\section{Results for Case 3}

The third case is realized with the single synchronous machine under load. The corresponding power curves have been investigated in depth. The assesment on the tests have been realized in terms of noise damping and power quality improvement.

The speed deviation curves according to the cases are given in Fig. 16. In line with various tests, it is found that hyperchaotic blackouts have not caused to occur more oscillations in SMIB system. But it overly increased the peak value of the speed deviation as Table 2 and it reversed the direction of the oscillations in the speed deviations. The PSS rarely had a negative effect on counteracting the hyperchaotic blackout. The PSS sometimes increased the occurrence and magnitude of oscillations in speed deviation.

Electrical power in the SMIB system under hyperchaotic blackout is shown in Fig. 17. The PSS has been damped noises and improved power quality as it can be seen in Fig 18. However, the instabilites in power could not be filtered completely. In both cases, standard power of the power system has been run out in terms of steady state stability.

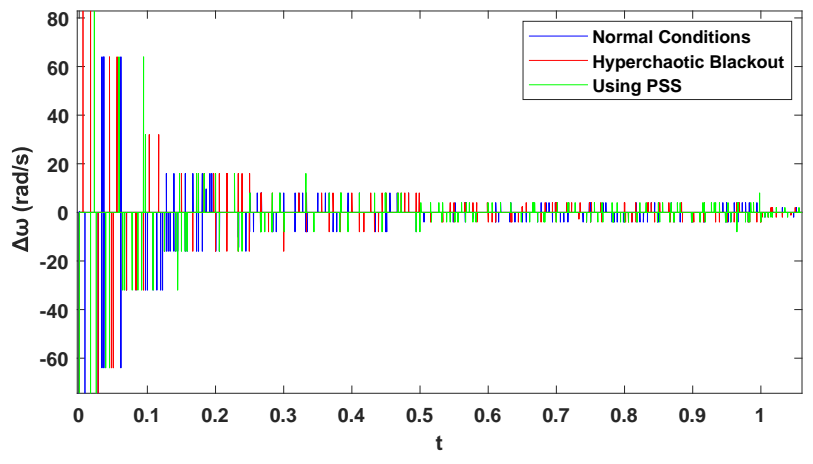

Figure 16 Speed deviation of the generator in a SMIB system that is excited by hypcerhaotic system

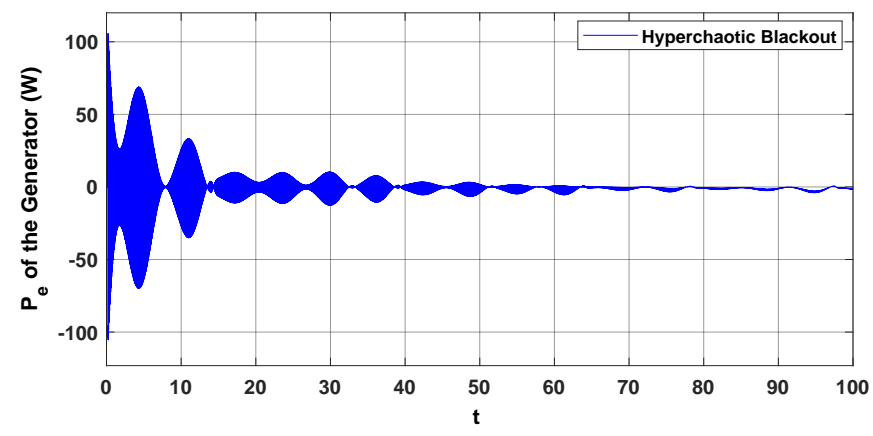

Figure 17 Electrical power in the generator under hyperchaotic blackout condition

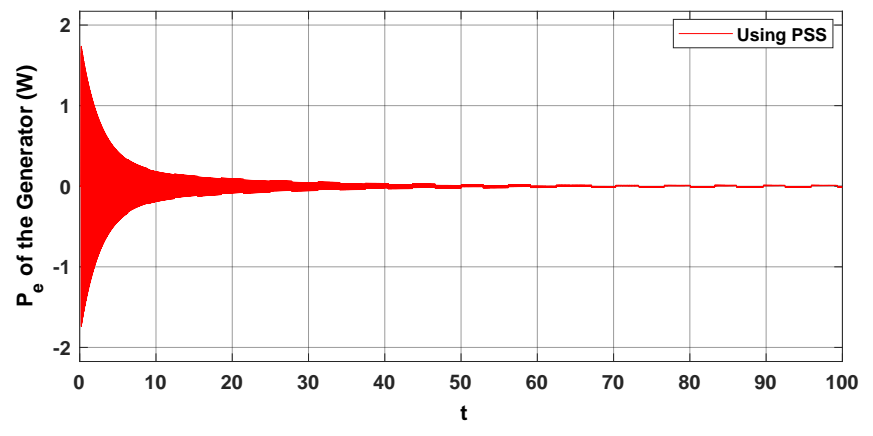

Figure 18 Damping characteristic of electrical power in the generator under hyperchaotic blackout condition 


\section{Summary Findings for Cases}

As a result, the peak values of the well-known controllers against the proposed blackout is summarized in Table 4. PSS and AVR have slightly regulated the hyperchaotic noise in infinite bus. PID controller has damp out the oscillations better than that of them. PID controlled PSS shows the best damping rate amongst the mentioned controllers. This inference is made given that infinite bus system with hyperchaotic excitation.

In the SMIB system, the output voltages are shown in Fig. 19. The normal effective system voltage is a $220 \mathrm{~V}$. Against the hyperchaotic noise, AVR has provided a great voltage stability. After about 0.2 seconds of oscillation, AVR has provided steady stability. PSS and PID has shown virtually same effects in terms of transient stability. Even though the PID has provided more damping than that of PSS in the long term. The PSS is seen to cause the system unstable in the very long term.

Table 4 Deviation values for the infinite bus system

\begin{tabular}{lllll}
\multicolumn{4}{c}{ Peak Overshoot $(\Delta w(t)(\mathrm{rad} / \mathrm{s}))$} \\
\hline $\begin{array}{l}\text { Without } \\
\text { Controller }\end{array}$ & AVR & PSS & $\begin{array}{l}\text { PID con- } \\
\text { trolled } \\
\text { PSS }\end{array}$ \\
\hline Normal & $222 \mathrm{e}-06$ & $219 \mathrm{e}-06$ & $215 \mathrm{e}-06$ & $155 \mathrm{e}-06$ \\
Hyperchaotic & 0.2342 & 0.2393 & 0.177 & 0.169 \\
\hline
\end{tabular}

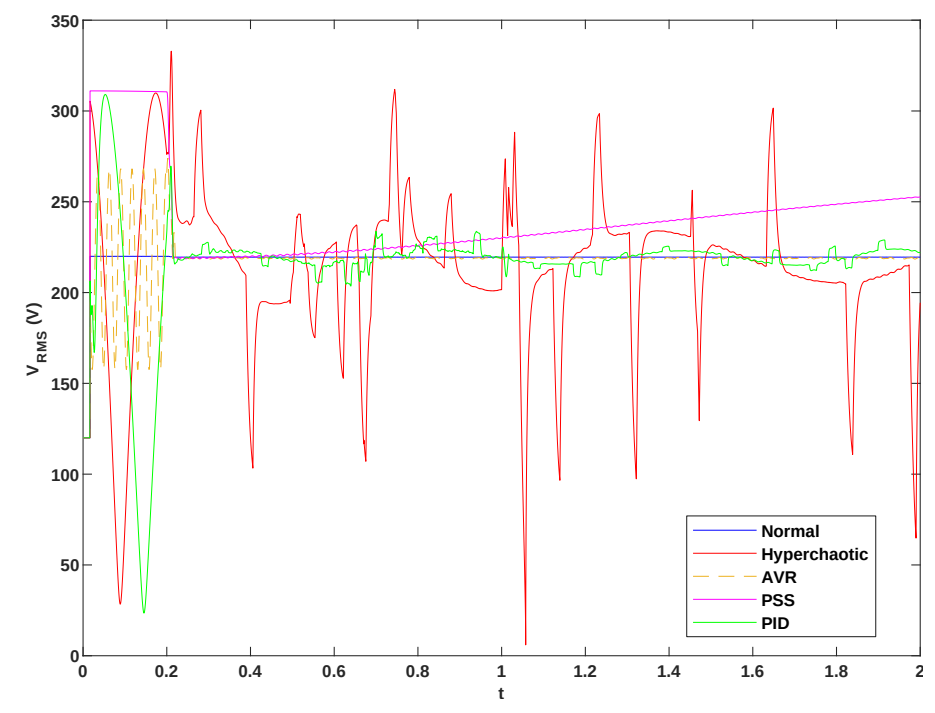

Figure 19 Effective value of the voltage in hyperchaotic noised SMIB system

\section{RESULTS AND DISCUSSION}

This study proposes a novel assesment in power system stability for the so-called hyperchaotic noise. Hyperchaotic noise is obtained from an existing system by implementing into the controllers. The test has been realized in the systems that have 11 buses, infinite buses and single machine. The stability analyses of the selected systems have been investigated according to the restorers such as PSS, PID contoller and AVR. That restorers are investigated whether it maintains against hyperchaotic blackouts. The mentioned analyzes have been realized in cases of nonchaotic, hyperchaotic and hyperchaotic with controller. The effects of the hyperchaotic blackouts in various systems have been presented. As a primary apparatus, the AVR could not immensely prevent the devastating hyperchaotic noises. But, the AVR have showed a great performance in providing voltage stability. The PSS have counteracted the amidst of hyperchaotic blackout in the power systems. The hyperchaotic noise damping rate of the PSS has been close to of PID controller. However, the PID controlled PSS has provided steady stability and small signal stability.

\section{Conflicts of interest}

The author declares that there is no conflict of interest regarding the publication of this paper.

\section{LITERATURE CITED}

Ahsan, H. and M. D. Mufti, 2020 Comprehensive power system stability improvement with rocof controlled smes. Electric Power Components and Systems 48: 162-173.

Chen, H.-K., T.-N. Lin, and J.-H. Chen, 2005 Dynamic analysis, controlling chaos and chaotification of a smib power system. Chaos, Solitons \& Fractals 24: 1307-1315.

Chiang, H.-D., C.-W. Liu, P. P. Varaiya, F. F. Wu, and M. G. Lauby, 1993 Chaos in a simple power system. IEEE Transactions on Power Systems 8: 1407-1417.

Das, P., P. C. Gupta, and P. P. Singh, 2021 Bifurcation, chaos and pid sliding mode control of 3-bus power system. In 2020 3rd International Conference on Energy, Power and Environment: Towards Clean Energy Technologies, pp. 1-6, IEEE.

DELAVARİ, H. and E. BAYAT, 2015 Comparison of different techniques for tuning of power system stabilizer. Cumhuriyet Üniversitesi Fen-Edebiyat Fakültesi Fen Bilimleri Dergisi 36: 248-257.

Demello, F. P. and C. Concordia, 1969 Concepts of synchronous machine stability as affected by excitation control. IEEE Transactions on power apparatus and systems 88: 316-329.

Dong, J., S. Li, S. Wu, T. He, B. Yang, et al., 2017 Nonlinear observerbased robust passive control of doubly-fed induction generators for power system stability enhancement via energy reshaping. Energies 10: 1082.

Ekinci, S. and B. Hekimoglu, 2018 Parameter optimization of power system stabilizer via salp swarm algorithm. In 2018 5th international conference on electrical and electronic engineering (ICEEE), pp. 143-147, IEEE.

Fonzin Fozin, T., P. Megavarna Ezhilarasu, Z. Njitacke Tabekoueng, G. Leutcho, J. Kengne, et al., 2019 On the dynamics of a simplified canonical chua's oscillator with smooth hyperbolic sine nonlinearity: hyperchaos, multistability and multistability control. Chaos: An Interdisciplinary Journal of Nonlinear Science 29: 113105.

Harb, A. M. and N. Abdel-Jabbar, 2003 Controlling hopf bifurcation and chaos in a small power system. Chaos, Solitons \& Fractals 18: 1055-1063.

Huang, R., R. Diao, Y. Li, J. Sanchez-Gasca, Z. Huang, et al., 2017 Calibrating parameters of power system stability models using advanced ensemble kalman filter. IEEE Transactions on Power Systems 33: 2895-2905.

Jamal, A., S. Suripto, and R. Syahputra, 2017 Power flow optimization using upfc based on neuro-fuzzy method for multi-machine power system stability. International Journal of Applied Engineering Research (IJAER) 12: 898-907. 
Kumar, R., R. Singh, H. Ashfaq, S. K. Singh, and M. Badoni, 2021 Power system stability enhancement by damping and control of sub-synchronous torsional oscillations using whale optimization algorithm based type-2 wind turbines. ISA transactions 108: 240 256.

Li, C. and G. Chen, 2004 Chaos and hyperchaos in the fractionalorder rössler equations. Physica A: Statistical Mechanics and its Applications 341: 55-61.

Li, Y., W. K. Tang, and G. Chen, 2005 Hyperchaos evolved from the generalized lorenz equation. International Journal of Circuit Theory and Applications 33: 235-251.

Liu, Z., C. Wu, J. Wang, and Y. Hu, 2019 A color image encryption using dynamic dna and 4-d memristive hyper-chaos. IEEE Access 7: 78367-78378.

Matsumoto, T., L. Chua, and K. Kobayashi, 1986 Hyper chaos: laboratory experiment and numerical confirmation. IEEE Transactions on Circuits and Systems 33: 1143-1147.

Nangrani, S. and S. Bhat, 2018 Fractional order controller for controlling power system dynamic behavior. Asian Journal of Control 20: 403-414.

Rech, P. C., 2017 Hyperchaos and quasiperiodicity from a fourdimensional system based on the lorenz system. The European Physical Journal B 90: 1-7.

Rossler, O., 1979 An equation for hyperchaos. Physics Letters A 71: 155-157.

Rössler, O. E. and C. Letellier, 2020 Hyperchaos. In Chaos, pp. 55-62, Springer.

Sahu, P. R., P. K. Hota, and S. Panda, 2018 Power system stability enhancement by fractional order multi input sssc based controller employing whale optimization algorithm. Journal of Electrical Systems and Information Technology 5: 326-336.

Sajjadi, S. S., D. Baleanu, A. Jajarmi, and H. M. Pirouz, 2020 A new adaptive synchronization and hyperchaos control of a biological snap oscillator. Chaos, Solitons \& Fractals 138: 109919.

Sauer, P. W. and M. A. Pai, 1998 Power system dynamics and stability, volume 101. Wiley Online Library.

Sharma, A., L. Nagar, N. Patidar, M. Kolhe, S. Nandanwar, et al., 2017 Minimizing uncertainties with improved power system stability using wide area fuzzy-2 logic based damping controller. In 2017 3rd International Conference on Computational Intelligence $\mathcal{E}$ Communication Technology (CICT), pp. 1-5, IEEE.

Sheikh, A. F. and S. K. Starrett, 2015 Comparison of input signal choices for a fuzzy logic-based power system stabilizer. In 2015 North American Power Symposium (NAPS), pp. 1-6, IEEE.

Singh, N. and P. Agnihotri, 2018 Power system stability improvement using facts devices. International Journal of Advance Research and Development 3: 171-176.

Tian, K., C. Bai, H.-P. Ren, and C. Grebogi, 2019 Hyperchaos synchronization using univariate impulse control. Physical Review E 100: 052215.

Vaidyanathan, S., C. Lien, W. Fuadi, M. Mamat, et al., 2020 A new 4-d multi-stable hyperchaotic two-scroll system with noequilibrium and its hyperchaos synchronization. In Journal of Physics: Conference Series, volume 1477, p. 022018, IOP Publishing.

Van Dai, L., D. Duc Tung, T. Le Thang Dong, and C. Le Quyen, 2017 Improving power system stability with gramian matrix-based optimal setting of a single series facts device: feasibility study in vietnamese power system. Complexity 2017.

Wang, X. and M. Wang, 2008 A hyperchaos generated from lorenz system. Physica A: Statistical Mechanics and its Applications 387: 3751-3758.
Xiu, C., R. Zhou, S. Zhao, and G. Xu, 2021 Memristive hyperchaos secure communication based on sliding mode control. Nonlinear Dynamics 104: 789-805.

Yu, F., L. Liu, B. He, Y. Huang, C. Shi, et al., 2019 Analysis and fpga realization of a novel $5 \mathrm{~d}$ hyperchaotic four-wing memristive system, active control synchronization, and secure communication application. Complexity 2019.

Yu, Y., H. Jia, P. Li, and J. Su, 2003 Power system instability and chaos. Electric power systems research 65: 187-195.

Yuan, W., X. Yang, W. Guo, and W. Hu, 2017 A double-domain image encryption using hyper chaos. In 2017 19th International Conference on Transparent Optical Networks (ICTON), pp. 1-4, IEEE.

Zhu, S. and C. Zhu, 2020 Secure image encryption algorithm based on hyperchaos and dynamic dna coding. Entropy 22: 772.

How to cite this article: Ozturk, H. An Analysis of Power System Stability against Hyperchaotic Noises and Blackouts. Chaos Theory and Applications, 3(2), 67-76, 2021. 